\title{
Study on the Water Inrush of the Underplate in the Mining Process of Kuting Coal Mine
}

\author{
Xinglin Wen \\ China Key Laboratory Breeding Base \\ of Mine Hazard Prevention and \\ Control of Education \\ Shandong University of Science and \\ Technology \\ Qingdao, China \\ 14635230@qq.com
}

\author{
Rumeng Wang \\ China Key Laboratory Breeding Base \\ of Mine Hazard Prevention and \\ Control of Education \\ Shandong University of Science and \\ Technology \\ Qingdao, China \\ 1547197072@qq.com
}

\author{
Yao Wang \\ China Key Laboratory Breeding Base \\ of Mine Hazard Prevention and \\ Control of Education \\ Shandong University of Science and \\ Technology \\ Qingdao, China \\ 369732597@qq.com
}

\begin{abstract}
Based on mining in working face floor karst collapse column, the damage of surrounding rock and the water inrush of GeTing coal floor of concealed karst collapse column as the research object, using numerical simulation software FLAC3D for mining stress field and plastic failure zones in the process of vertical direction and the vertical displacement change analysis, analyzed the different forward distance of concealed under the floor water inrush process of karst collapse column. The results show that the surging forward distance, increased the plastic range, the karst collapse column bottom vertical displacement increasing, when the coal floor of the plastic zone and the plastic zone of karst collapse column connection.
\end{abstract}

Keywords-concealed collapse column, numerical simulation, floor water inrush, pushing distance, plastic failure, Geting coal mine

\section{THE INTRODUCTION}

According to data released by the national energy statistics bureau, China's total energy consumption totaled 4.36 billion tons of standard coal in 2016 [1]. The country's 48.5 percent of coal mines are threatened by water damage, 26 billion $t$ coal reserves are threatened by water, and 18.6 percent of the reserves in the north are threatened by the karst water in the bottom plate [2]. From 2000 to 2016, there were 1475 accidents in mine accidents, resulting in 5,273 deaths. In 2016, the mortality rate of coal million tons in China was 0.156 , compared with that in developed countries [3]. Karst collapse column is widely developed in north China coal field, and the problem of water inrush is becoming more and more serious.

In order to solve the problem of water inrush, domestic experts have studied different aspects of theory, experiment and numerical simulation. In the formation of the collapse column, the gravity collapse theory, gypsum dissolution theory, vacuum absorption theory and hydrothermal genesis were proposed. On the mechanism of collapse column water bursting, Yin shang, Mr First proposed the theory of thick wall barrel, $\mathrm{Xu}$ Jinpeng of collapsing column water transmitting mechanism of mechanics criterion is deduced and zhen-hua li and li see waves of collapse column water inrush similar simulation experiment [4]. In this paper, from the mining of coal floor damage and of activation of karst collapse column, under different forward distance of mining coal face roof and floor stress field and plastic failure zones, the change of stress field and seepage field is studied, revealing backplane concealed the general rule of karst collapse column water inrush.

\section{THE CRITERION OF PLASTIC FAILURE OF SURROUNDING ROCK OF TOP FLOOR OF COAL SEAM}

According to the mechanical properties of the coal rock mass, the mohr-coulomb model is adopted this time, and its failure criterion is the mohr-coulomb and maximal tensile stress criterion, and its failure criterion expression formula is as follows:

$$
f_{s}=\sigma_{1}-\sigma_{3} \frac{1+\sin \varphi}{1-\sin \varphi}+2 C \sqrt{\frac{1+\sin \varphi}{1-\sin \varphi}}
$$

Where: is the maximum principal stress, MPa;is the minimum principal stress, $\mathrm{MPa}$; is the internal friction Angle of the rock mass, $\mathrm{o}$; $\mathrm{C}$ is the cohesion of rock mass, $\mathrm{MPa}$.When the rock mass occurs shear failure (), the rock mass reaches the yield limit, and if there is a large pressure, the rock mass will deform. The tensile stress yield condition is:

$$
f_{t}=\sigma_{t}-\sigma_{3}
$$

In the formula: ${ }^{\sigma_{t}}$ for tensile strength, MPa;At $f_{s}<O$, the coal bed rock mass produced shear failure; At $f_{t}>O$, the coal bed rock mass produced tensile stress damage.

\section{BUILD THE NUMERICAL MODEL OF BURIED KARST COLLAPSE COLUMN OF FLOOR BOARD}

\section{A. Mining engineering and hydrogeological}

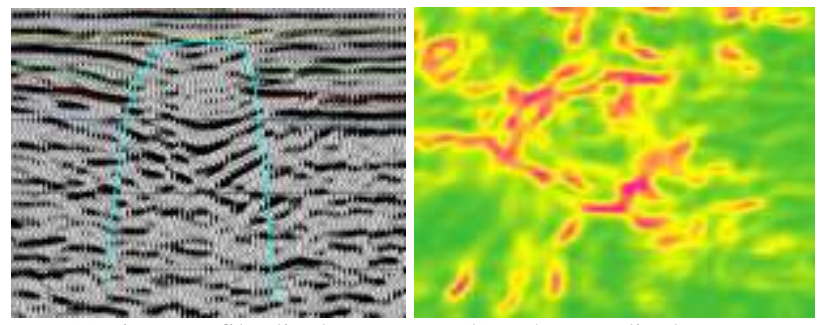

(a) time profile display

(b) coherent display

FIG. 1 Collapse column of SX1

The development strata in the mining area were successively: the ordovician system, the benxi group, taiyuan group, the second Permian shanxi group and the fourth layer of clay. The coal seam is located in the 16 and 17 coal seam of taiyuan formation, and the coal seam is located at $30 \sim 80 \mathrm{~m}$ of the aohui aquifer, and 16 and 17 coal are under the threat of the oxy aquifer. The top of the roof is mudstone, siltstone and fine sandstone, and the bottom plate is made of mudstone and fine sandstone. 
According to the $3 \mathrm{~d}$ seismic exploration, three collapse columns were found, among which the other two were smaller than the larger ones. Located at the edge of the southwest corner of the measuring area, it fell to 13 ash and augray, and $30 \mathrm{~m}$ below the coal bottom plate. In the region, the length of the long axis is the NW direction, the length is $80 \mathrm{~m}$, the short axis is NE direction, the length is $60 \mathrm{~m}$, the area is $2436 \mathrm{~m} 2$, and FIG. 1 is the collapse column of SX1.

\section{B. Boundary conditions and scheme design of numerical model}

Table 1 Mechanical parameters of rock strata.

\begin{tabular}{|c|c|c|c|c|c|c|}
\hline $\begin{array}{l}\text { Parameter } \\
\text { Lithology }\end{array}$ & $\begin{array}{l}\text { Elasti } \\
\text { cGPa }\end{array}$ & $\begin{array}{l}\text { Poisson' } \\
\text { s ratio }\end{array}$ & $\begin{array}{l}\text { Tensile } \\
\text { MPa }\end{array}$ & $\underset{\mathrm{kg} / \mathrm{m}^{-3}}{\rho}$ & $\begin{array}{l}\text { porosi } \\
\text { ty } \eta\end{array}$ & $\begin{array}{c}\text { Permeability } \\
\text { coefficient } \\
\mathrm{K} / 10^{-3} \mathrm{~ms}^{-1}\end{array}$ \\
\hline $\begin{array}{c}\text { Fine } \\
\text { sandstone }\end{array}$ & 3 & 0.30 & 1.6 & 1600 & 0.09 & 0.250 \\
\hline siltstone & 32 & 0.35 & 3.6 & 2700 & 0.17 & 0.024 \\
\hline marl & 15 & 0.26 & 2.2 & 2500 & 0.16 & 0.043 \\
\hline Coalseam & 2 & 0.23 & 1.6 & 1500 & 0.24 & 0.101 \\
\hline mudstone & 3 & 0.30 & 1.6 & 1600 & 0.18 & 0.028 \\
\hline $\begin{array}{c}\text { Fine } \\
\text { sandstone }\end{array}$ & 18 & 0.25 & 2.1 & 2400 & 0.12 & 0.033 \\
\hline limestone & 17 & 0.34 & 2.0 & 2000 & 0.13 & 0.050 \\
\hline aquifer & 20 & 0.11 & 5.1 & 3000 & 0.26 & 0.370 \\
\hline column & 2.7 & 2.7 & 0.3 & 1700 & 0.6 & 0.440 \\
\hline
\end{tabular}

In model, both the left and right sides are horizontal constraints, and the direction of the working face is along the $\mathrm{X}$ axis. The top pressure is replaced by the equivalent load of $10 \mathrm{MPa}$; The water pressure of the aquifer is $2.4 \mathrm{MPa}$ and the rock mass saturation is 1 . After mining, the boundary of the working face is zero, and the stope after recovery is the seepage boundary [8].. Model size is . The height of the collapse column is $40 \mathrm{~m}$ and the diameter is $30 \mathrm{~m}$. The cutting eye is located at $100 \mathrm{~m}$ of the center line of the collapse column, and the boundary is left at $50 \mathrm{~m}$. The working face is pushed from left to right, and each time is pushed by $20 \mathrm{~m}$. The physical and mechanical parameters of rock are shown in table 1 , and the model is shown in FIG. $2^{[9-10]}$.

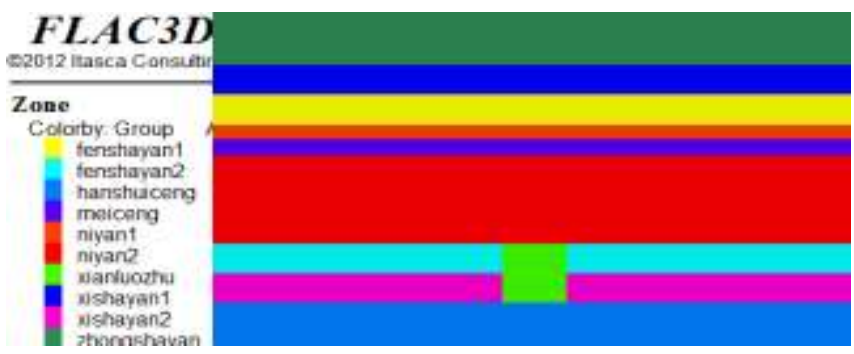

Fig. 2Schematic diagram of the collapse column of bottom plate

\section{USING THE TEMPLATE NUMERICAL SIMULATION MODEL AND ANALYSIS}

\section{A. Vertical stress analysis of rock.}

1) As can be seen from FIG. 2, the stress distribution of the surrounding rock is relatively clear. The stress concentration around the collapse column is $16.4 \mathrm{MPa}$, while the internal stress of the collapse column is relatively small, and the vertical stress is $9.5 \mathrm{MPa}$. In the initial surrounding rock stress state, the vertical stress is less than the surrounding rock stress in the intact rock strata, indicating that the collapse column is a natural low stress concentration zone. Under the influence of mining stress concentration factor increasing, when more than rock strength, can make the collapse column surrounding rock mass is extremely prone to damage, seepage pressure in the aquifer water easily happened.

2)Through the analysis of FIG. 3, it can be seen that the stress redistribution is caused by the backstoping of the working face, and the stress concentration is formed in the front of the working surface, and the unloading pressure zone and the pressurized zone are formed in the top floor of the collapse column. When the stoping face is pushed to $20 \mathrm{~m}$, and the distance is about $60 \mathrm{~m}$, the thrust distance has less influence on the stress distribution of the collapse column. When moving to $80 \mathrm{~m}$, the stress area overlaps when it is near the collapse column.

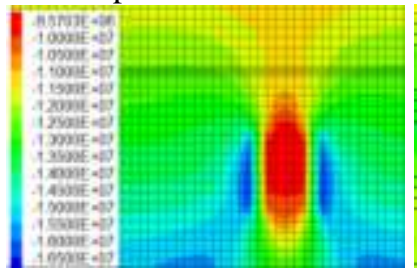

(a) Before mining

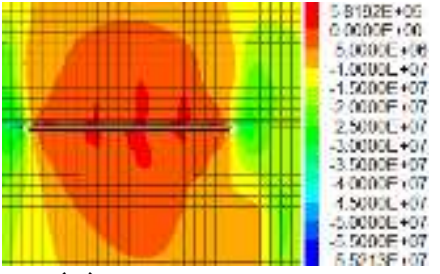

(b) Promote the $100 \mathrm{~m}$
FIG. 3 Vertical stress of surrounding rock in propulsion

3) Maximum vertical stress concentration in the working face in both sides of the mined-out area, the reason is that of coal seam wall rock affected by mining working face of, the original rock squeeze stress increases, when more than floor when the tensile strength of thin sandstone and mudstone, the plastic damage occurs, in the face after pushing rock stress release and stress decreases, and as the creep time tends to be stable gradually, can see clearly under the influence of mining working face slab stress to wall rock, the vertical stress of the three regions pressurization area - unloading area - the dynamic changes of the plateau, in line with the mining stope floor damage balance theory analysis.

\section{B. Analysis of plastic failure zone}

1) When the working face mining face not through the collapse column, along with the increase of the working face advancing distance increase plastic failure depth of coal seam floor, when reach the collapse column bottom plastic damage reached the maximum depth; After the working face through the backplane of collapse, as the working face away from the collapse column, floor plastic damage depth and gradually decreases, and when the working face advancing to $80 \mathrm{~m}$, coal floor of the plastic zone and the plastic zone of collapse column and docking, prone to floor water inrush accident collapse column.

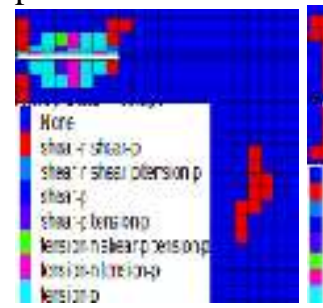

(a) Advance $40 \mathrm{~m}$ FIG. 4 Plastic

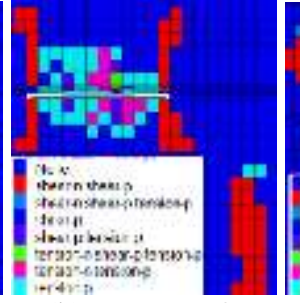

(b) promote $60 \mathrm{~m}$

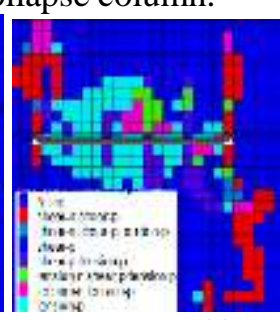

(c) promote $100 \mathrm{~m}$ propulsion

2) Before mining collapse column junction with the 
grey aquifer about $5 \mathrm{~m}$ in the plastic damage area, and with the increase of working face advancing distance, backplane collapse column of the plastic zone increasing, when advancing about $60 \mathrm{~m}$, collapse column inside the cylinder with the grey aquifer conduction. And with the increasing distance, it is very easy to destroy the aquifer at the upper part of the collapse column under the action of mining and water pressure splitting, so that thewater in aquifer is gushing out.

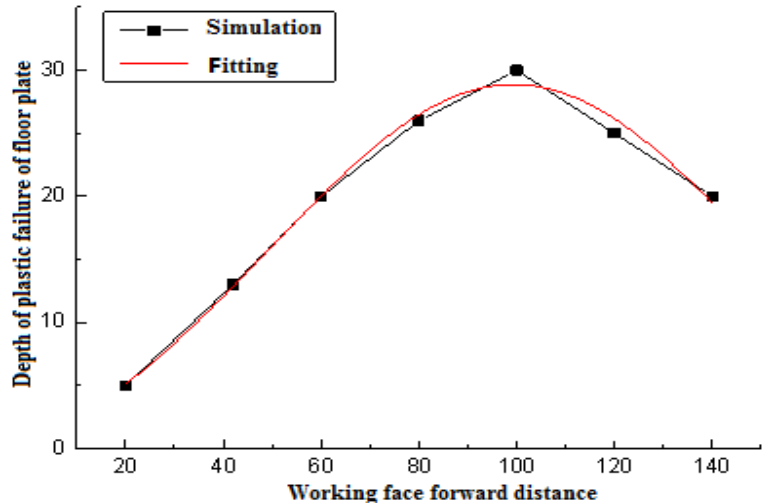

FIG. 5 The change curve of plastic failure depth of bottom plate under different propulsion distances

C. Analysis of displacement field of rock

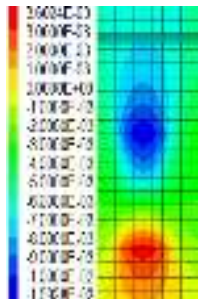

(a)Before

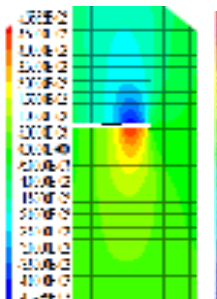

(b) To 60m

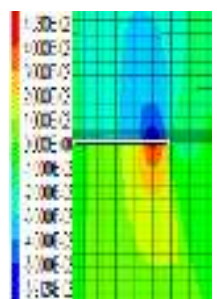

(c) To $80 \mathrm{~m}$

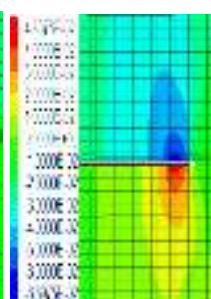

(d)To $100 \mathrm{~m}$
FIG. 6 Vertical displacement diagram in propulsion process

1) Before the excavation of the initial collapse column and its surrounding rock, compared to collapse column is opposite bigger, internal displacement in the vertical direction of displacement is given priority to, and at the top of the fall of the vertical displacement of surrounding rock is less than at the bottom of the collapsing column; When the excavation is started, the displacement of the vertical displacement of the roof surrounding rock is greater than the vertical displacement of the surrounding rock.

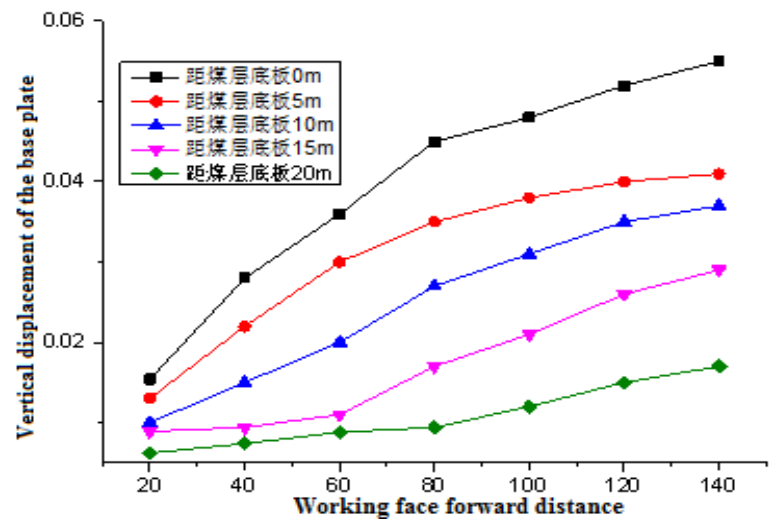

FIG. 7 The vertical shift value of the floor surrounding rock in the propulsion process

2) With the increase of advance distance and collapse column is more and more close, when mining working face advancing to $80 \mathrm{~m}$, the bottom of vertical displacement of surrounding rock significantly offset in the direction of collapse column, the floor and collapse column vertical direction of the stress field of surrounding rock stack, the plastic zone and docking.

\section{Change analysis of seepage field}

1) Within the former mining aquifer and collapse column in a relatively stable state, the mining at the top of the seepage have occurred, before the show before the collapse column wall rock in mining due to its structure and the influence of confined water pressure seepage damage has occurred.

2) With the increasing distance, the seepage height and scope of the collapse column head are constantly increasing. When $40 \mathrm{~m}$ is pushed, the seepage range of the roof of the collapse column reaches $20 \mathrm{~m}$. During the advance of $100 \mathrm{~m}$, the seepage range of the top of the rock drop column reached $25 \mathrm{~m}$, and the rock strata in the collapse column could easily be destroyed under the action of osmotic water pressure, thus reducing the water separation capacity of the aquifer.

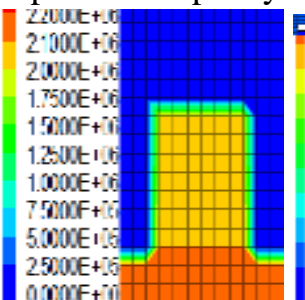

(a) Before

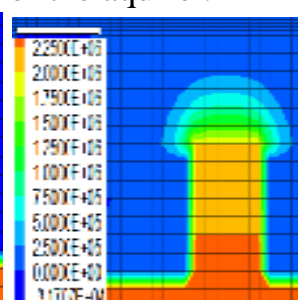

(b)Push 80m

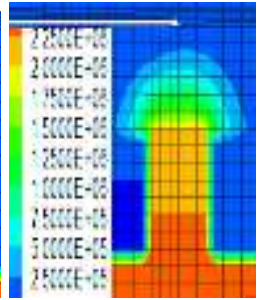

(d) $T$ To100m
FIG. 8 Seepage field diagram in the propulsion

\section{CONCLUSION}

By means of numerical simulation, the subsurface of the bottom plate is concealed, and the water of 17 coal is in danger of water bursting at the interval of $30 \mathrm{~m}$.

1) It is easy to shear and stretch damage on the bottom plate of the mining area and the collapse column near the mining side.

2) Affected by mining, with the increase of advance distance, surrounding rock stress concentration degree and scope gradually increased, the plastic range increases gradually, vertical displacement range increases gradually, should be the floor in front of the mining and collapse column grouting reinforcement renovation.

References:

[1] wang jiachen, a numerical simulation study on mechanism in the collapse column [J]. Journal of mining and safety engineering, 2009,26(02):140-144.

[2] liu zhixin, the application of integrated mine geophysical exploration technology $[\mathrm{J}]$. Geophysical exploration and geochemical exploration 2008(02):212-215.

[3] yue jianhua, the application of direct current detection of roadway in detection of collapse column [J]. Journal of China mining university,2003(05):13-15

[4] zhang wenquan. Fisher discriminant analysis model of water inrush hazard [J]. Journal of coal, 2013 , 38(10): 1831-1836.

[5] zhu zonkui. Research on the evaluation method of water inrush hazard based [J]. mining and safety 2013,30(06): 9-916.

[6] wu qiang. Evaluation of water in coal seam floor variable weight model [J]. Journal of coal,2013,38(09):1516-1521. 
[7] wang yancang. The formation mechanism and distribution of the collapse column of block in qinshui basin [J].petroleum exploration, 2010,15(02):45-48+85. 